\title{
University Reference Work After the War
}

The president of the Association of College and Reference Libraries elaborates an earlier message by calling attention to activities that may require new emphasis in the years ahead.

$\mathrm{U}^{\mathrm{s}}$

NDER the general educational plan for ex-service men recommended by the National Resources Planning Board ${ }^{1}$ and the American Council on Education, ${ }^{2}$ many more men and women will be attending high school and college during the next few years than ever before. The program of the individual student may include courses leading to general, technical, or professional education, depending upon his qualifications and his interests. The student body of a university will be made up as before of young students who have come to college just out of high school, the graduate students who have continued straight through college into graduate work, and the graduate students who have returned after several years of teaching or business experience. Added to this will be the service men and women who are returning to the classrooms after mustering out and those who have been employed in the many war industries. Faculty who have remained in the university and taught regular students, the V-I2's, the Army Specialized Training Program, and the Civil Air Training Service and the

\footnotetext{
1 National Resources Planning Board. Report of the Conference on Postwar Readjustment of Civilian and Military Personnel. Demobilization and Readjust.

ment. June 1943 . General Education. Washington, American Council on.Education, 1944. (Series I. Reports of Committees and Conferences, no. 18.)
}

faculty who have been in military service or advising in governmental capacities in Washington, will be returning to their positions in the universities.

All of these people need the best library service possible. Our library methods must keep pace with the educational program of the university. The reference room is the pivotal point that should improve or maintain its reputation. In fact, it should do all possible to increase its influence and importance in the lives of the student body, the faculty, and the research staff. Those who have been in military service will have been under Army and Navy discipline. They will want to get away from all unnecessary red tape in the use of the library, the need for which is hard for an outsider to understand.

A little self-surveying might be good for all of us. In training people to live and to study and to teach in the postwar world, the university libraries have an important role. They should take stock of their own organization and see what is unimportant in the plans of the particular library. With the much larger student body in the next few years, there will be more and more demand upon the resources of the library, and every member of the staff should attempt to be a little more efficient in his work. This hardly seems possible in the case of many people. Perhaps, though, even the most efficient persons can think of ways to save a little time in one place in 
order to do something else that will help make the library more effective in the postwar years. This is especially important for the reference librarians, for they, with the circulation staff, are the ones who give the public the impression of the whole library. Readers judge a library by the staff they meet, not by the staff behind the scenes who do the important work of preparing books for the shelves.

We must have those books that are valuable in following up the interests of the men who have been in Europe, the Pacific, Africa, and out-of-the-way foreign parts. We must have reference materials as well as books of description and history and probably translations of foreign literatures. We must have titles on the current topics being discussed in the daily newspapers, such as social and economic security, world peace, and the new discoveries in science. We must also have a good collection of material on ways to spend leisure time both profitably and interestingly.

These books should be made available promptly, that is, the processing departments must work quickly so that items of current interest may not be held up for weeks waiting for Library of Congress cards. After the books are ready for circulation, we should do everything we can to make it possible for the students to find them easily. Special shelves for new titles, short lists of interesting new books, book news in the college paper-are possible ways of advertising. We must remember that there are many of the faculty and students who do not like to ask questions if they can possibly find the material they want by themselves.

In addition to books, we must plan for the use of instructional films and records in classrooms and in the library. The use of audio-visual methods of instruction is growing by leaps and bounds. It is an important matter to be considered in planning a library for the future. The men coming back from service have been having a good deal of their instruction in this manner.

The reference staff should watch more carefully than ever the bibliographical publications listing new material in all fields that might be useful. The book budget should always be stretched to include the purchase of timesaving bibliographical material. They should watch to see if new indexes should be undertaken or if new publications should be indexed in those already being published.

Reference librarians, will be eternally grateful for such ventures as the Union List of Serials and the list of American Newspapers, $1821-1936$. They all mean the saving of hours and hours of correspondence with other libraries all over the country to locate material. Such published lists, as well as the great union cata$\log$ in the Library of Congress, make research possible with greater speed and ease than ever before. They are tangible evidence of the value of cooperation.

What other cooperative undertakings are there that we should all support, either nationally or regionally? They seem like large pieces of work when first suggested and when carried out, but their value should be considered over a period of years. Would union lists of university publications, of master's theses and doctoral dissertations, or of foreign newspapers in American libraries, be helpful?

We can do still more in helping students to help themselves. Many colleges and universities do have courses on the use of the library and its resources, but there are still institutions that lack such systematic instruction. Students like to do things for themselves and they will enjoy the information they acquire that will enable them to

(Continued on page 14I) 
The instructor-librarian must learn to select "representative" materials. All sides of any question should be presented and, by counseling, the student can be trained to look for the signs which point to the attitude most useful for his purpose. A Great Teacher once said that a tree is known by its fruits. In the examination of materials dealing with a political system, for instance, this rule can be applied. It seems obvious that any political organization which prohibits sane vocal, physical, or mental expression is far from democratic. The student who is encouraged to be critical in his reading will not be too gullible.

Finally, the librarian should stand ready to assist the teacher in providing the physical setting necessary. In addition to shelf space for books, the teacher must have a seminar room and an office for consultation. Both of these rooms should be in or adjacent to the library. The physical needs of rooms and equipment are an important consideration, for we have found that enthusiasm in student and teacher varies according to the availability of the materials and the ease with which they are used.

To some observers the plan outlined above may seem to be nothing more than the regular seminar method. It is an adaptation, but its peculiar feature is the immediate guidance by the teacher. Assuming that most undergraduates are not qualified to do completely independent research, this procedure nevertheless lifts teacher and student above the level of the "dishing-out, lapping-up" process so common today.

It is a happy medium designed so that the teacher may have time to encourage the more serious student while preparing him to do graduate research. On the other hand, the student who is taking the course for general culture may read as much as he desires, while the "grade and credits" student may pursue his inclinations without inconveniencing the others.

In the last analysis, such a plan seems desirable because it brings together the two most important elements in the study of the social sciences-the library and the student.

\section{University Reference Work After the War}

\section{(Continued from page 107)}

be their own detectives and to use the various reference books with freedom of action and with skill. Some departments work a little bibliographical instruction into their courses. Well and good, but what about a general course that will teach the use of the card catalog and the periodical indexes, union catalogs, etc., graded according to the background and training of the student, perhaps covering simple tools the first year, the more advanced ones in the third year, and the specialized ones for the graduate student in a special field in the fourth year?

The already overbusy reference librarian is going to ask, "How can all this be done when we are already overcrowded with work?" Perhaps we need a little examination of our own activities. Are we doing tasks that some other department should be doing? Are we doing bibliographical work already covered by some printed bibliographical service for which we should be subscribing? What can we possibly leave out of our daily schedule that will enable us to have a few more minutes for reading book-reviewing periodicals and other bibliographical publications? With all our desire to push a little harder to make ourselves more efficient, however, we should never forget that our own friendly yet helpful manner is the important factor in working with faculty and students at this critical time in the readjustment of the lives of many young men and women. 